\title{
The effect of safer play equipment on playground injury rates among school children
}

\author{
Andrew W. Howard, Colin MacArthur, Andrew Willan, Linda Rothman, \\ Alexandra Moses-McKeag, Alison K. MacPherson
}

Abstract

Background: Changes to Canadian Standards Association (CSA) standards for playground equipment prompted the removal of hazardous equipment from 136 elementary schools in Toronto. We conducted a study to determine whether applying these new standards and replacing unsafe playground equipment with safe equipment reduced the number of school playground injuries.

Methods: A total of 86 of the 136 schools with hazardous play equipment had the equipment removed and replaced with safer equipment within the study period (intervention schools). Playground injury rates before and after equipment replacement were compared in intervention schools. A database of incident reports from the Ontario School Board Insurance Exchange was used to identify injury events. There were 225 schools whose equipment did not require replacement (nonintervention schools); these schools served as a natural control group for background injury rates during the study period. Injury rates per 1000 students per month, relative risks (RRs) and 95\% confidence intervals (Cls) were calculated, adjusting for clustering within schools.

Results: The rate of injury in intervention schools decreased from 2.61 (95\% Cl 1.93-3.29) per 1000 students per month before unsafe equipment was removed to 1.68 (95\% Cl 1.31-2.05) after it was replaced (RR $0.70,95 \% \mathrm{Cl} 0.62-0.78$ ). This translated into 550 injuries avoided in the post-intervention period. In nonintervention schools, the rate of injury increased from $1.44(95 \% \mathrm{Cl} 1.07-1.81)$ to $1.81(95 \% \mathrm{Cl} 1.07-2.53)$ during the study period (RR 1.40, 95\% Cl 1.29-1.52).

Interpretation: The CSA standards were an effective tool in identifying hazardous playground equipment. Removing and replacing unsafe equipment is an effective strategy for preventing playground injuries.

CMAJ 2005;172(11):1443-6 dren, away from traffic and other outdoor hazards. In addition, playground activities can enhance children's cognitive, physical and psychosocial skills. Playground safety is of concern to physicians, parents and injury prevention advocates. Of all playground injuries that result in a visit to a hospital emergency department, $27 \%$ $40 \%$ are fractures and 17\% require hospital admission - a greater frequency of admission than that associated with any other cause of pediatric injury except traffic. ${ }^{1-4}$ The results of an observational study in Wales showed that $90 \%$ of all playground injuries resulting in a visit to an emergency department were related to the playground equipment. ${ }^{1}$ As might be expected, playgrounds are the location within elementary schools with the highest injury rates and the most severe injuries. ${ }^{5}$ In a study conducted in Kingston, Ont., children were 12 times more likely to be injured in school playgrounds than in municipal playgrounds. ${ }^{3}$

Standards for playgrounds have been developed both in Canada $^{6}$ and internationally. ${ }^{7-12}$ The Canadian Standards Association (CSA) standards for the design, installation and maintenance of playgrounds and equipment were most recently revised in $1998 .{ }^{6}$ No published data exist on the relation between equipment standards and injury rates. If applying standards can identify unsafe playgrounds and, more importantly, reduce the rate of child injury, such standards would be a useful tool for school and municipal authorities responsible for playgrounds.

We sought to determine the effect of replacing unsafe playground equipment (as determined using the new CSA standards) on injury rates among school children.

\section{Methods}

The Toronto District School Board (TDSB) worked with an independent, qualified playground consultant to develop a methodology for assessing the compliance of all playground equipment in its jurisdiction with the 1998 CSA standards and 1990 CSA guidelines. Details of the methodology are given in the online appendix at www.cmaj.ca/cgi/content/full/172/11 /1443/DC1. In the spring of 2000, the same consultant assessed all playground equipment in TDSB elementary schools $(n=398)$ for CSA compliance and indicated whether the equipment in each case should be left as is, repaired or retrofitted, or removed and replaced. Two factors were considered in making the decision: the severity of injury that could result from using the equipment and, where equipment was noncompliant, the feasibility of achieving compliance through repair or retrofit.

The assessment identified 136 schools with playground equipment that represented a severe hazard (i.e., an imminent risk of serious and permanent injury, usually indicating risk of a fall from more than $1.5 \mathrm{~m}$ or a fall onto unsuitable surfacing), did not 
meet CSA standards and was impractical to retrofit to make safer (Fig. 1). The equipment was removed from all 136 schools in the summer of 2000. By Dec. 31, 2001, the equipment had been fully replaced in 86 schools, which constituted the intervention group; it had not been fully replaced in the remaining 50 schools, and they were excluded from analysis (Fig. 2). Injury rates before and after equipment replacement were compared in the intervention schools. A total of 225 schools had equipment that did not require replacement, and they constituted the nonintervention schools; injury rates in this group served as an indicator of stability of baseline injury rates in this natural experiment. A total of 34557 students attended the intervention schools, and 88417 attended the nonintervention schools. All schools included grades 1 through 6 and were public schools.

A database of incident reports from the Ontario School Board Insurance Exchange was used to identify all injury events occurring at TDSB schools between January 1998 and December 2002 inclusive. Information in the database is provided by school staff whenever an incident occurs in the school during school hours. The threshold for completing a report is "whenever medical or dental attention is required," and this includes injuries attended to by teachers or school staff, as well as those in which the child went home or to a health facility. We included all injuries to children 4-11 years of age that occurred within the school playground. Research assistants, blinded to the study purpose and date of injury (i.e., before or after equipment removal), coded all playground incidents on the basis of written descriptions from the database. Injuries where equipment was explicitly mentioned in the written description were flagged as "equipment related" for subanalysis.

Playground injury rates (injuries per 1000 children per month) were compared at the intervention schools and at the nonintervention schools before equipment removal and after equipment replacement. Person-time denominators used the average yearly enrollment in each school multiplied by the number of months that the school was in session. The same 10 -month calendar periods were selected before and after the intervention to avoid bias related to seasonal variation in injury. The pre-intervention period was from September 1999 to June 2000, and the postintervention period was from January 2002 to December 2002 (excluding July and August). To adjust for clustering within schools, injury rates and relative risks (RRs), along with their con-

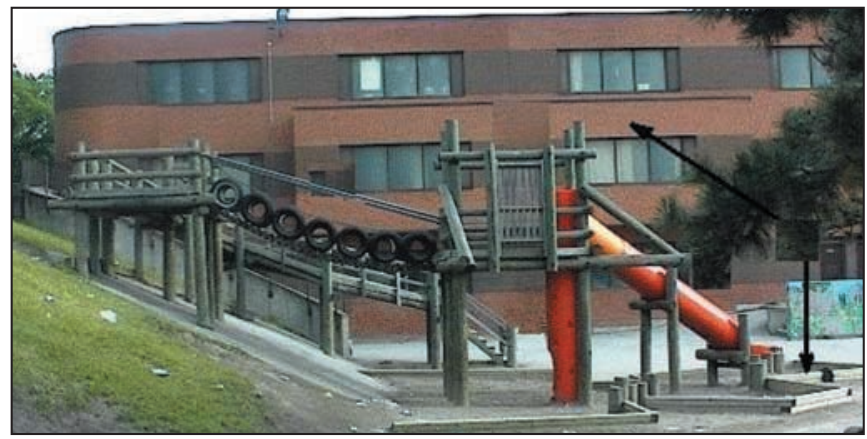

Fig. 1: An unsafe (above) and a safe (right) playground. In the unsafe playground, the height a child may fall from equipment is greater than $1.5 \mathrm{~m}$, the surface under the structure is bare earth and the surface on the hillside is concrete, even though it is an area where a child might fall. The equipment at this playground was removed and replaced. fidence intervals (CIs), were estimated using random-effect metaanalytic methods as proposed by Thompson and colleagues. ${ }^{13}$

Expected post-intervention injury rates in the intervention schools were calculated by multiplying the pre-intervention rates in intervention schools by the ratio of post-intervention to preintervention rates in the nonintervention schools. The proportion of injuries prevented (etiological fractions) ${ }^{14}$ were calculated by subtracting observed from expected rates and expressing the result as a percentage of the expected rate. The analysis was repeated for the subset of injuries flagged as equipment related.

\section{Results}

The injury rate in the intervention schools decreased from 2.61 (95\% CI 1.93-3.29) injuries per 1000 students per month before equipment removal to 1.68 (95\% CI 1.31-2.05) per 1000 per month after the equipment was replaced (RR 0.70, 95\% CI 0.62-0.78). This translated into 550 injuries avoided in the post-intervention period.

Cases where playground equipment was explicitly mentioned as the cause of injury accounted for roughly one-quarter of injuries overall. This subgroup was analyzed in the same way. The equipment-related injury rate in the intervention schools decreased from 0.58 (95\% CI 0.45-0.72) injuries per 1000 students per month before equipment removal to 0.44 (95\% CI $0.31-0.57)$ per 1000 per month after the equipment was replaced (RR 0.82, 95\% CI 0.66-1.03). This translated into 117 equipmentrelated injuries avoided.

Injury rates in the nonintervention schools increased from 1.44 (95\% CI 1.07-1.81) per 1000 per month before the intervention to 1.81 (95\% CI 1.07-2.53) per 1000 per month after the intervention (RR 1.40, 95\% CI 1.29-1.52). Equipment-related injury rates in the nonintervention schools also increased, from 0.25 (95\% CI 0.19-0.32) per 1000 per month before the intervention to 0.32 (95\% CI $0.25-0.39)$ per 1000 per month after the intervention (RR $1.15,95 \%$ CI $0.96-1.37)$.

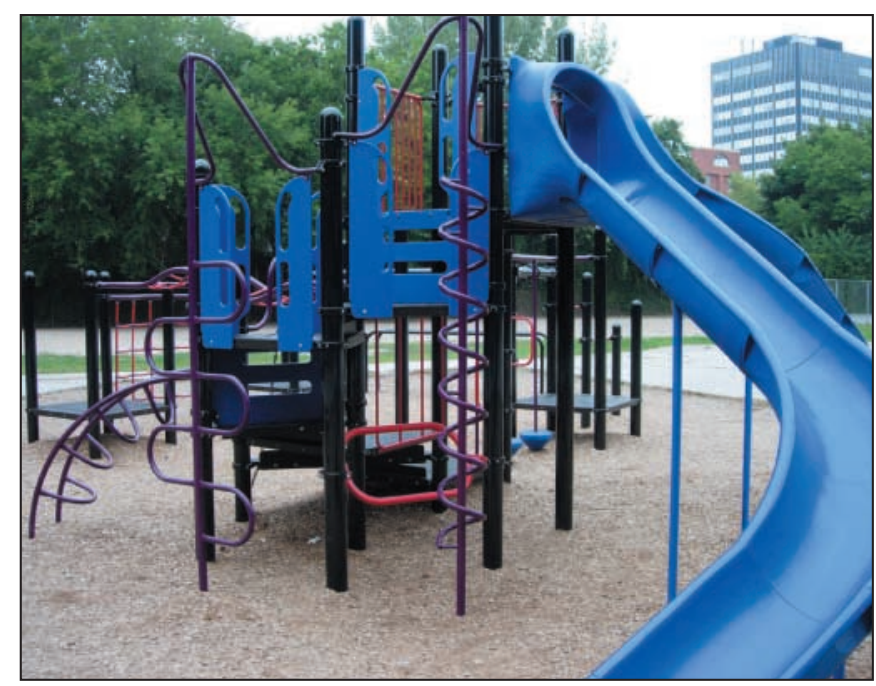




\section{Interpretation}

The results of this study show that the CSA standards were effective in identifying schools with unsafe playground equipment. Removing unsafe equipment and replacing it with equipment compliant with safety standards reduced the rate of playground injuries.

Other studies have evaluated interventions to facilitate safe playground environments. ${ }^{15-18}$ In general, these interventions have involved a variety of assessments of playground hazards followed by educational programs. None evaluated the effects of a large-scale intervention on a population of children. Our data allowed us to compare injury rates in the intervention schools and in the nonintervention schools and to assess trends in playground injuries over time.

Why did the injury rates fall in the intervention schools and rise in the nonintervention schools? Possible explanations include changes in the physical environment, in exposure, in supervision or in reporting. We believe that the change in physical environment is the best explanation. The physical environment improved in the intervention schools, where injury rates dropped. It was possibly deteriorating in nonintervention schools, where injury rates increased. A reduction in injuries not recorded as being "equipment related" is explained by the fact that the entire outdoor environment was addressed in those schools undergoing equipment removal and replacement. Additional dangers such as fragmented asphalt, poorly drained and icy areas, steep embankments and degraded borders were repaired or safely landscaped during equipment replacement.

There are limitations to our study. First, we could not assess the amount of exposure to equipment or nonequipment play. However, we suspect that, if anything, the novelty of new equipment would increase exposure, which would thereby strengthen our findings. This may explain why the number of equipment-related injuries was still slightly higher in the intervention schools than in the nonintervention schools after the intervention. Second, we did not measure supervision, which may have changed. However, to have an effect on injury rates, supervision would need to have increased in the intervention schools yet decreased in the nonintervention schools, and we think this is unlikely. Third, information on injuries was obtained from reports of teachers and other school employees, whose thresholds for recording and reporting injuries may have changed during the study. It is difficult to imagine how equipment type would systematically influence the likelihood of reporting injuries. If the intervention sensitized school employees to playground safety, we would expect increased reporting at the intervention schools, which would not explain the observations.

The CSA standards were an effective tool in identifying hazardous playground equipment. Removal and replacement of unsafe equipment is an effective strategy for preventing playground injuries.

This article has been peer reviewed.

From the Department of Population Health Sciences, The Hospital for Sick Children (Howard, MacArthur, Willan, Rothman, Moses-McKeag), and the School of Kinesiology and Health Science, York University, and the Institute for Clinical Evaluative Sciences (MacPherson), Toronto, Ont.

Competing interests: None declared.

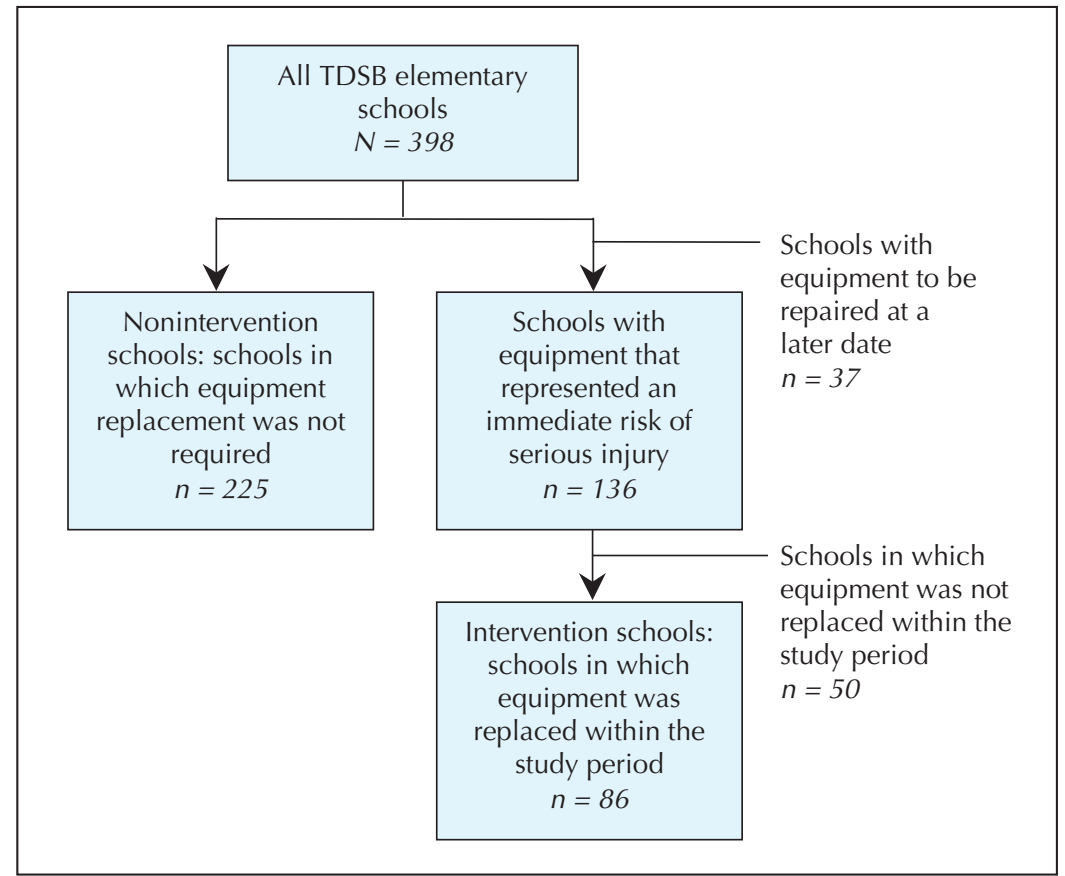

Fig. 2: Determining the intervention and nonintervention groups of schools. TDSB $=$ Toronto District School Board. 
Contributors: Andrew Howard conceived the study and contributed to the study design, analysis and interpretation of the data, and drafting and critical revision of the manuscript. Colin MacArthur contributed to the analysis, interpretation of the data and critical revision of the manuscript. Andrew Willan contributed to the analysis, interpretation of the data and critical revision of portions of the manuscript. Linda Rothman and Alexandra Moses-McKeag contributed to the study design, data collection, portions of data analysis and interpretation, and drafting of the manuscript. Alison MacPherson contributed to the study conception and design, analysis and interpretation of the data, and critical revision of the manuscript. All of the authors approved the final version of the manuscript.

\section{References}

1. Mott A, Evans R, Rolfe K, Potter D, Kemp KW, Sibert JR. Patterns of injuries to children on public playgrounds. Arch Dis Child 1994;71(4):328-30.

2. Yamamoto LG, Wiebe RA, Matthews WJ, Jr. A one-year prospective ED cohort of pediatric trauma. Pediatr Emerg Care 1991;7(5):267-74.

3. Mowat DL, Wang F, Pickett W, Brison RJ. A case-control study of risk factors for playground injuries among children in Kingston and area. Inj Prev 1998;4(1):39-43.

4. Illingworth C, Brennan P, Jay A, Al-Rawi F, Collick M. 200 injuries caused by playground equipment. BMF 1975;4(5992):332-4.

5. Boyce WT, Sobolewski S, Sprunger LW, Schaefer C. Playground equipment injuries in a large, urban school district. Am 7 Pub Health 1984;74(9):984-6.

6. Canadian Standards Association. A guideline on children's playspaces and equipment: A national standard of Canada. Mississauga, Ont.: The Association; 1998.

7. Standard consumer safety performance specification for playground equipment for public use [ASTM F1487-01e1]. West Conshohocken, PA: American Society for Testing and Materials; 2003.
8. Standard guide for ASTM standards on playground surfacing [ASTM F2223-04] West Conshohocken, PA: American Society for Testing and Materials; 2003.

9. Playground equipment. General safety requirements and test methods [BS EN 1176-1]. London: British Standards Institution; 1998.

10. Impact absorbing playground surfacing. Performance requirements and test methods [BS 7188]. London: British Standards Institution; 1998.

11. Playground equipment - Part 1: General safety requirements and test methods [EN 1176-1]. Brussels: European Committee for Standardization (Comité Européen de Normalisation); 1998

12. Playground surfacing - Specifications, requirements and test methods [AS 4422 1996/Amdt 1-1999]. Sydney: Standards Australia; 1999.

13. Thompson SG, Pike SD, Hardy RJ. The design and analysis of paired cluster randomised trials: an application of meta-analysis techniques. Stat Med 1997; 16:2063-79.

14. Hennekens CH, Buring JE. Epidemiology in medicine. 1st ed. Boston: Little, Brown; 1987.

15. McEvoy M, Montana B, Panettieri M. Intervention to ensure a safe playground environment. 7 Pediatr Health Care 1996;10:209-16.

16. Laraque DBB, Davidson L, Welborn C. The Central Harlem Playground Injury Prevention Project: a model for change. Am 7 Pub Health 1994;84:1691-2.

17. Sacks JJ, Brantley MD, Holmgreen P, Rochat RW. Evaluation of an intervention to reduce playground hazards in Atlanta child-care centers. Am $\mathcal{F}$ Pub Health 1992;82(3):429-31.

18. Day L, Ozanne-Smith J, Cassell E, Li L. Evaluation of the Latrobe Valley Better Health Injury Prevention Program. Inj Prev 2001;7(1):66-9.

Correspondence to: Dr. Andrew W. Howard, The Hospital for Sick Children, 555 University Ave., Toronto ON M5G 1X8; fax 416 813-6414; andrew.howard@sickkids.ca

\section{Clinical practice guidelines FOR THE CARE AND TREATMENT OF BREAST CANCER}

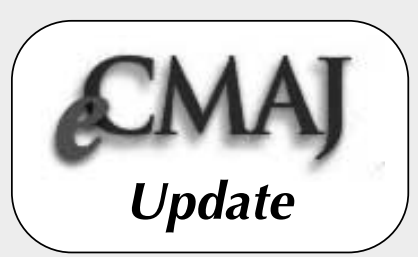

In February 1998 CMAJ and Health Canada published 10 clinical practice guidelines for the care and treatment of breast cancer, along with a lay version designed to help patients understand more about this disease and the recommended treatments. These guidelines are being revised and updated as new evidence becomes available, and the series is being extended to cover new topics. The complete text of the new and updated guidelines is available at:

\section{www.cmaj.ca/cgi/content/full/158/3/DC1}

REVISED:

Guideline 3: Mastectomy or lumpectomy? The choice of operation for clinical stages I and II breast cancer [July 23, 2002]

Guideline 5: The management of ductal carcinoma in situ [Oct. 2, 2001]

Guideline 6: Breast radiotherapy after breastconserving surgery [Feb. 18, 2003]

Guideline 7: Adjuvant systemic therapy for women with node-negative breast cancer [Jan. 23, 2001]

Guideline 8: Adjuvant systemic therapy for women with node-positive breast cancer [Mar. 6, 2001]

Guideline 9: Follow-up after treatment for breast cancer [May 10, 2005]

Guideline 10: The management of chronic pain in patients with breast cancer [Oct. 30, 2001]
NEW:

Guideline 11: Lymphedema [Jan. 23, 2001]

Guideline 12: Chemoprevention [June 12, 2001]

Guideline 13: Sentinel node biopsy [July 24, 2001]

Guideline 14: The role of hormone replacement therapy in women with a previous diagnosis of breast cancer [Apr. 16, 2002]

Guideline 15: Treatment for women with stage III or locally advanced breast cancer [Mar. 16, 2004]

Guideline 16: Locoregional post-mastectomy radiotherapy [Apr. 13, 2004] 